\title{
THE DISTRIBUTION OF GEOSPIZA DIFFICILIS IN RELATION TO G. FULIGINOSA IN THE GALÁPAGOS ISLANDS: TESTS OF THREE HYPOTHESES
}

\author{
Dolph Schluter and Peter R. Grant \\ Division of Biological Sciences, University of Michigan, Ann Arbor, Michigan 48109
}

Received June 18, 1981. Revised March 3, 1982

David Lack (1947, 1969) argued that interspecific competition for food has played a significant role in the adaptive radiation of Darwin's Finches. He regularly invoked competition to explain morphological and distributional patterns in the finches. An important example is the altitudinal distribution of Geospiza difficilis in relation to G. fuliginosa (Fig. 1). Low elevation, dry islands in the Galápagos are occupied by one of the two species, but never both. Islands possessing a highland vegetation zone may have both species but here they are altitudinally segregated, with $G$. fuliginosa occupying the lowlands and $G$. difficilis the highlands. Lack noted the morphological similarity of these finch species and suggested that $G$. difficilis had been excluded on low islands or altitudinally restricted on high islands through competition for food by $G$. fuliginosa wherever the species had come into contact. Bowman (1961), however, suggested instead that the unique food requirements of the two species and differences in food supply among islands, once known, would suffice to explain the pattern.

The ecology of these two species was recently investigated over a calendar year on Isla Pinta where they coexist (Schluter, $1982 a, 1982 b)$. Surveys conducted on this island and on Islas San Salvador and Fernandina (unpubl. observ.) revealed that $G$. difficilis and $G$. fuliginosa are not allopatric as Lack believed. Their altitudinal ranges overlap extensively year-round although they are not coextensive (Fig. 2). Detailed observations of behavior and abundance strongly suggested that interspecific competition between them is presently weak. Food supply was probably limiting over part of the year, but interspecific aggression (e.g., territoriality) was not observed, and their diets and feeding positions were very different. The distributions and abundance of both species along the elevational gradient on Isla Pinta could easily be interpreted as being determined by the availability of their different foods.

The question of whether past competition has influenced the distribution of $G$. difficilis in relation to $G$. fuliginosa remains. Significantly, $G$. difficilis varies in size and shape from island to island. For example on Isla Genovesa the species resembles the missing $G$. fuliginosa (Lack, 1947; see also Grant, in press). Possibly $G$. difficilis has adapted to exploit lowland environments on islands without a highland zone, and it is this lowland form which cannot coexist with $G$. fuliginosa. Observed differences in sympatry might also be the result of past competition. Lack's competition hypothesis is therefore still consistent with the observed insular distributions of these two species.

Here we report the results of a field study which tested the argument that competition has influenced the distributions on low islands, against two alternative hypotheses based on Bowman's (1961) suggestions. We use information gained on diets, density and food supply of $G$. difficilis and G. fuliginosa on Pinta (Schluter, 1982b) to predict attributes of the two species in allopatry. The three hypotheses make different predictions, and these are tested with field data. The allopatric populations we used were $G$. difficilis on Genovesa and G. fuliginosa on Marchena (Fig. 2).

\section{HYPOTHESES}

The Fixed Food Requirements hypothesis (FFR) is that distributions of both species are determined by their different 


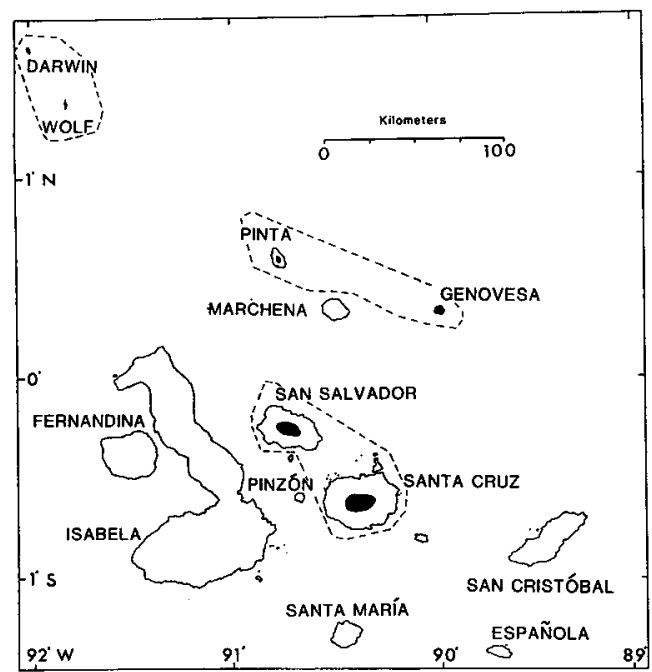

FIG. 1. Distribution of G. difficilis (blackened areas) in relation to $G$. fuliginosa (white) in the $\mathrm{Ga}$ lapagos archipelago reported by Lack (1947). Dashed lines delimit the ranges of three $G$. difficilis subspecies. Geospiza difficilis has gone extinct on Santa Cruz, Santa Maria and San Cristobal, but is known to be present also in the highland zone of Fernandina (see Grant and Schluter, in press).

food requirements. These requirements are assumed not to vary among different island populations of a given species. Requirements are expected to be absent from islands where the species does not occur. From this hypothesis we expect that the diet, density, and food supply of each species should be essentially the same in allopatry and in sympatry.

A second hypothesis, that of Variable Food Requirements (VFR), also explains the distributions in terms of the food requirements of each species. However these requirements are not fixed, as in the above hypothesis, but may vary among islands because of local adaptation to different food supply conditions. Thus, the distribution of each species is explained by the distribution of a relatively wide range of "suitable foods." The present extent of the inter-island variation in food requirements is assumed to be limited: to account for allopatry on low islands the suitable ranges for both $G$. fuliginosa and $G$. difficilis are assumed to be different. In contrast to FFR, this hypothesis predicts that diet and

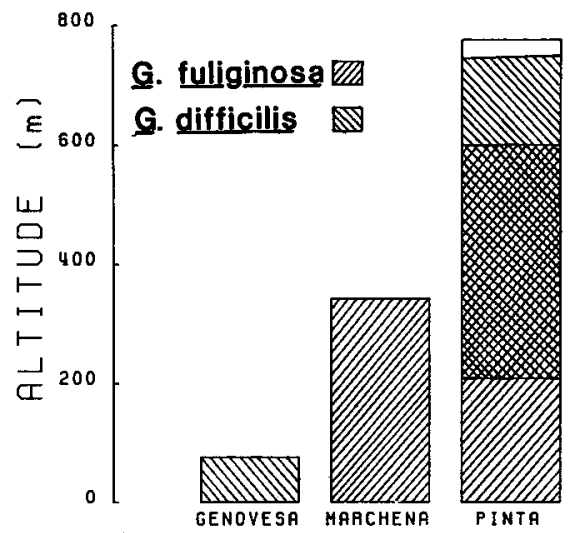

FIG. 2. Approximate altitudinal ranges of $G$. $f u$ liginosa and $G$. difficilis on three Galapagos islands. Species ranges on Pinta were rescaled to correspond to the altitudes given in Wiggins and Porter (1971) (see Methods).

density of a species may vary among islands. It also predicts that food supply of islands where only $G$. difficilis is found should differ from food supply on islands where only $G$. fuliginosa is present. These first two hypotheses (FFR and VRF) are restatements of Bowman's (1961) arguments about the importance of food supply in determining distributions (see also Abbott et al., 1977).

The third hypothesis is that of competitive exclusion, i.e., that the distribution of $G$. difficilis in relation to $G$. fuliginosa is explained in part by competitive interactions (between the two species) and not by food supply alone. Unlike the first two hypotheses it predicts greater similarity in allopatry than has been observed in sympatry: on low islands where the food supplies should be quite similar, the feeding behavior and density of the two species should also be similar.

All three hypotheses are in agreement regarding $G$. fuliginosa on Marchena: its diet and density there should essentially correspond to its diet and density in lowland sites on Pinta. We therefore include Marchena information on this species only as a check on the procedures. We use $G$. difficilis data from Genovesa and food supply data from all three islands to discriminate among the hypotheses, by 
TABLE 1. Dates of field study in 1979. In the text the dates are referred to by the months given in parentheses.

\begin{tabular}{llcc}
\hline \hline Season & \multicolumn{1}{c}{ Island } & \multicolumn{1}{c}{ Dates } & $\begin{array}{c}\text { No. study } \\
\text { sites }\end{array}$ \\
\hline Wet & Pinta & 20 Jan.-28 Feb. (February) & 6 \\
Wet & Genovesa & 3 Mar.-23 Mar. (March) & 2 \\
Wet & Marchena & 24 Mar.-16 Apr. (April) & 2 \\
Wet & Pinta & 26 Apr.-29 May (May) & 6 \\
Dry & Pinta & 9 Aug.-15 Sept. (August) & 6 \\
Dry & Genovesa & 17 Sept.-3 Oct. (September) & 3 \\
Dry & Marchena & 4 Oct.-27 Oct. (October) & 2 \\
Dry & Pinta & 28 Oct.-3 Dec. (November) & 6 \\
\hline
\end{tabular}

matching observations with the different predictions.

\section{Methods}

The study was conducted on Islas Pinta (Abingdon), Genovesa (Tower) and Marchena (Bindloe) in the Galápagos Archipelago during both wet and dry seasons (Grant and Boag, 1980) of 1979. On Pinta six 1 ha study sites were established on a transect up the southern slope. This transect spanned Pinta's three major vegetation zones: arid, transition, and humid forest (Wiggins and Porter, 1971). In addition, two sites of the same size were established on the south side of Marchena, one near the coast and a second on a hillside $3 \mathrm{~km}$ distant $(170 \mathrm{~m})$. On Genovesa two 1 ha sites were established near Bahía Darwin, in the same location of previous investigators (Abbott et al., 1977; Smith et al., 1978). A third site was added later (Table 1). Altitudes of all sites were determined using a pocket altimeter. In the case of Pinta these values were found to contradict those published elsewhere (e.g., maximum altitude is reported as $777 \mathrm{~m}$ in Wiggins and Porter [1971] yet we and Adsersen [1976] have recorded it as $650 \mathrm{~m}$ ). Except where indicated we use our own values.

The sequence and duration of visits to the three islands are shown in Table 1 . For convenience the dates are hereafter referred to by the month which, in each visiting period, included the majority of days (Table 1). From January to May seed, fruit, and arthropod availability were highest, and finches were breeding throughout most of this season. No breeding was observed from August to December. At this time finches were probably food limited, as suggested by decreases in population sizes which corresponded with declines in food supply (Schluter, 1982b; see also Smith et al., 1978).

Three methods of censusing finch abundance were used. First, in the breeding season territories of adult males were mapped and counted to provide estimates of breeding density. Second, relative density within sites was assessed at each visit by using mist net captures. Two nets were used per site in February, and three nets were used thereafter. Nets were unfurled at dawn in each site and these remained open for $2.1 \mathrm{~h}$ each, on each of two successive mornings. In the dry season (Table 1) a third technique was used, census by observation, where all finches encountered within $10 \mathrm{~m}$ of the observer along predetermined transects in sites were recorded. Results from netting and census transects were correlated $(r=.67, G$. $f u$ liginosa; $r=.64, G$. difficilis; $n=12$, $P<.05)$.

Diets were quantified on systematic walks through sites by recording the amount of time that finches spent feeding on specific foods, up to a maximum of 300 s per individual. Observations were made only on adult birds in the wet season. This was done to avoid a possible bias: young juveniles tended to be less efficient than adults at handling certain food items, and they often modified their behavior in the presence of the observer. An exception was made for $G$. difficilis on Pinta, where both 
TABLE 2. Finch distributions on Pinta in the early wet and late dry season, 1979.

\begin{tabular}{cccccr}
\hline \hline & & \multicolumn{4}{c}{ Total finch captures per net } \\
\cline { 3 - 6 } & Altitude & \multicolumn{2}{c}{ G. difficilis } & \multicolumn{2}{c}{ G. fuliginosa } \\
\cline { 3 - 6 } Site & $(\mathrm{m})$ & February & November & February & November \\
\hline 1 & 110 & .0 & .3 & 4.5 & 10.0 \\
2 & 180 & .5 & .0 & 3.0 & 6.3 \\
3 & 225 & 1.5 & 1.3 & 7.0 & 10.6 \\
4 & 285 & 1.5 & 1.0 & 10.5 & 7.0 \\
5 & 400 & 3.0 & 2.3 & .5 & 24.3 \\
6 & 510 & 1.5 & 1.7 & .0 & .7 \\
\hline
\end{tabular}

juvenile and adult data were recorded. This was necessary to allow diet description for low altitude sites where adult $G$. difficilis were uncommon. However there was no indication of a bias in this case: adult and juvenile diets were not different in sites where both age groups were present. In the dry season adults and birds born that year could not be distinguished on the basis of diet or feeding efficiency, and so all finches encountered were recorded.

Food supply was assessed during all visits. Twenty-five (occasionally 50) $1 \mathrm{~m}^{2}$ random quadrats were sampled per site, and in each the percent cover of plant species and the number of seeds, fruits and flowers on the vegetation were determined. In addition, exposed seeds were counted and all litter and surface soil were removed from the ground in two subquadrats of $0.125 \mathrm{~m}^{2}$ total area. Seeds and invertebrates were later removed from the litter/soil samples and litter volume was measured. Dry weights of seeds and invertebrates were assessed in the laboratory.

\section{RESULTS}

\section{Fixed Food Requirements Hypothesis}

The first hypothesis (FFR) explains the distribution of $G$. difficilis in relation to $G$. fuliginosa by the distribution of speciesspecific food requirements. To account for the presence of $G$. difficilis on Genovesa by this argument, we expect that sites there are similar in food characteristics to those areas on Pinta where this species occurs commonly. The distributions of both species on Pinta are compared in Table 2. Over most of the year $G$. difficilis reached its greatest density in the high-elevation sites, and it was usually uncommon in the lowlands. We thus expect sites on Genovesa to be more similar to highland Pinta than to lowland sites. Table 3 compares some attributes of sites on these two is-

TABLE 3. Habitat characteristics of different sites on Pinta (P), Genovesa (G) and Marchena (M). Similarity in the composition of seed-producing plant genera was computed using Sprenson's (1948) index. Values $\geqslant$ .50 are given in boldface. Litter volume is the average over all sampling dates (Table 1). Differences among sites in litter and invertebrates were significant in all seasons (Kruskal-Wallis, $\mathrm{P}<.001$ ).

\begin{tabular}{|c|c|c|c|c|c|c|c|c|c|c|c|}
\hline \multirow[b]{2}{*}{ Site } & \multirow{2}{*}{$\begin{array}{l}\text { Altitude } \\
\text { (m) }\end{array}$} & \multicolumn{6}{|c|}{ Similarity } & \multirow{2}{*}{$\begin{array}{c}\text { No. } \\
\text { Plant } \\
\text { Genera }\end{array}$} & \multirow{2}{*}{$\begin{array}{c}\text { Mean } \\
\text { litter } \\
\text { volume } \\
\left(1 / \mathrm{m}^{2}\right)\end{array}$} & \multicolumn{2}{|c|}{$\begin{array}{l}\text { Density ground } \\
\text { invertebrates }\left(\mathrm{mg} / \mathrm{m}^{2}\right)\end{array}$} \\
\hline & & $\mathrm{G}_{1}$ & G2 & G3 & M1 & M2 & P1 & & & Wet season $^{a}$ & Dry season \\
\hline G1 & 20 & - & & & & & & 13 & 1.7 & 16.8 & 15.2 \\
\hline G2 & 20 & .73 & - & & & & & 9 & 1.9 & 18.4 & 7.2 \\
\hline G3 & 10 & .78 & .84 & - & & & & 10 & 2.6 & - & 14.4 \\
\hline M1 & 10 & .50 & .42 & .56 & - & & & 15 & 0.8 & .8 & 13.6 \\
\hline M2 & 170 & .40 & .29 & .45 & .81 & - & & 12 & 0.8 & 5.6 & 13.6 \\
\hline P1 & 110 & .45 & .36 & .39 & .55 & .50 & - & 36 & 2.0 & 4.0 & 10.4 \\
\hline $\mathbf{P} 2$ & 180 & .36 & .30 & .39 & .52 & .42 & .72 & 31 & 2.3 & 8.0 & 9.6 \\
\hline P3 & 225 & .38 & .28 & .36 & .49 & .43 & .69 & 34 & 4.9 & 33.6 & 24.0 \\
\hline P4 & 285 & .32 & .25 & .34 & .35 & .37 & .59 & 31 & 6.8 & 33.6 & 41.6 \\
\hline P5 & 400 & .24 & .21 & .20 & .17 & .25 & .39 & 20 & 10.0 & 95.2 & 202.4 \\
\hline P6 & 510 & .16 & .06 & .12 & .21 & .22 & .27 & 24 & 8.3 & 54.4 & 290.4 \\
\hline
\end{tabular}

\footnotetext{
a Gastropods were not sampled in this season and so are not included here.
} 


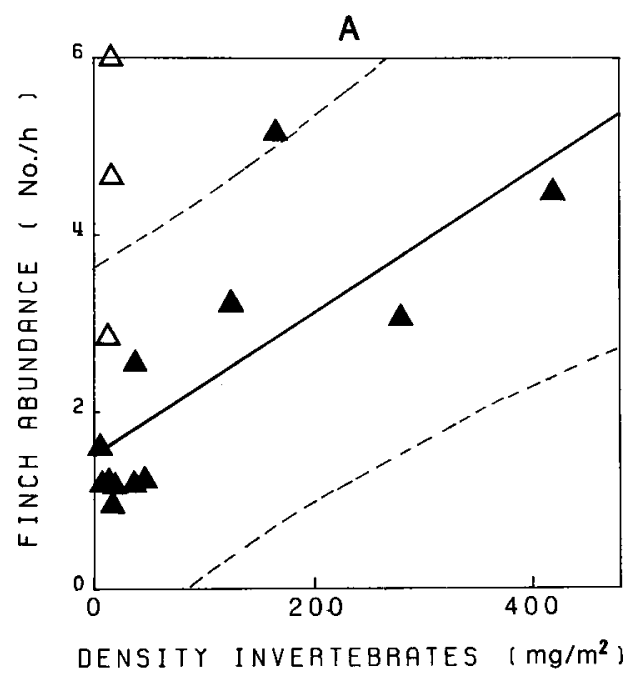

B

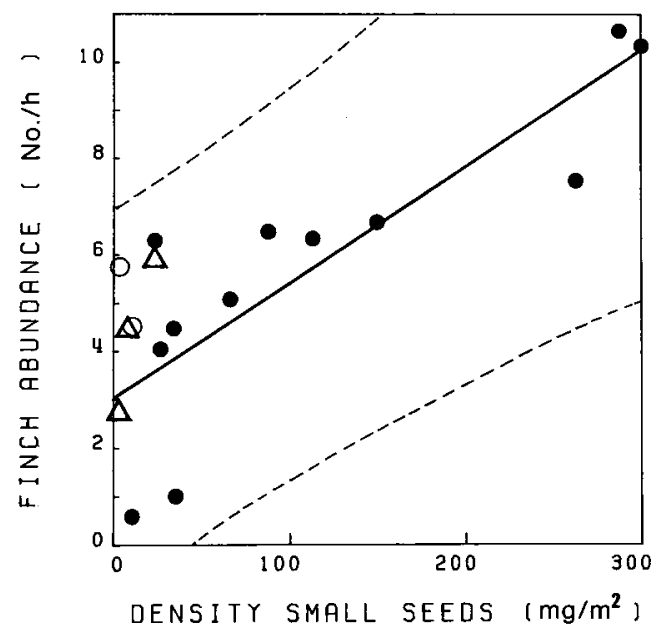

FIG. 3. The mean numbers of finches encountered on census walks regressed on the density of preferred foods on Pinta in the dry season. Dashed lines delimit the $95 \%$ confidence region for Y-estimates. (A) Regression for $G$. difficilis on Pinta (A) with points for this species on Genovesa $(\triangle)$ superimposed. The independent variable refers only to ground invertebrates. (B) Regression for G. fuliginosa on Pinta (O) with points for this species on Marchena (O) and for $G$. difficilis on Genovesa $(\triangle)$ superimposed. See Table 5 for definition of small seeds.

lands. Similarity values for the composition of seed-producing plant genera in different sites indicate that Genovesa is considerably more similar to low-altitude
WET SEASON

DRY SEASON

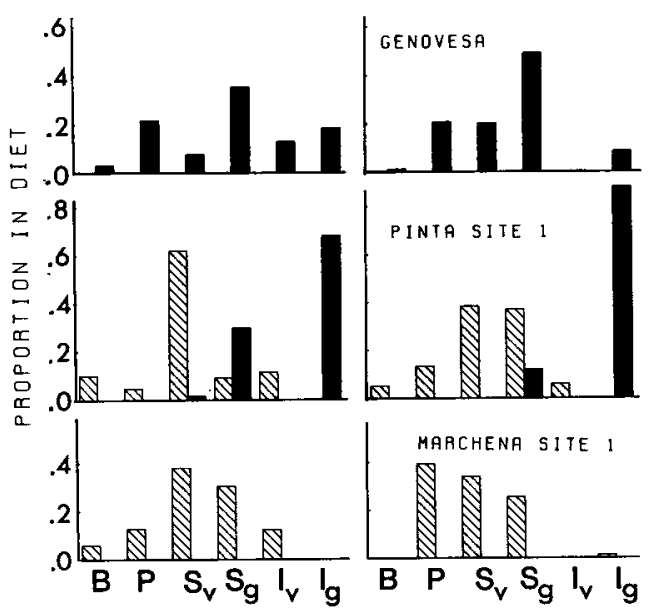

FIG. 4. Diet of $G$. difficilis (solid bars) and $G$. fuliginosa (hatched bars) in lowland sites. Genovesa values are unweighted averages of the proportion of time spent feeding on the six foods in the two (wet season) or three (dry season) grids. Pinta diets shown are from May (wet season) and November (dry season). Diet categories are berries/arils $(B)$, pollen/nec$\operatorname{tar}(P)$ and seeds $\left(S_{v}, S_{g}\right)$ and invertebrates $\left(I_{v}, I_{g}\right)$ from the vegetation and ground. Seeds on the vegetation $\left(\mathrm{S}_{\mathrm{v}}\right)$ include all seeds and fruits obtained from the parent plant or exposed parts of it (e.g., fallen flower heads). Exposed seeds on rock surfaces, or seeds in the soil and litter are included in the ground category $\left(\mathrm{S}_{\mathrm{g}}\right)$.

sites on Pinta in this measure than to highaltitude sites. Indeed Genovesa is most similar to the lowest site on Pinta, where $G$. difficilis is not common (Table 2) and where it does not breed.

Geospiza difficilis consumed seeds in all sites on Pinta, but the major constituent of its diet year-round was invertebrates, removed mainly from the litter (see Fig. 4, and later). Table 3 compares sites in litter volume and the density of ground invertebrates. As shown, the litter on Genovesa is very shallow. The majority of the substrate there is bare rock, and litter volume is as low as the barest sites on Pinta. The density of ground invertebrates is correspondingly low on Genovesa, especially in the dry season. This contrasts with a substantially greater litter volume and ground invertebrate abundance at higher elevations on Pinta (Table 
TABLE 4. Diet similarity between populations of finches. Diet items were classified into three categories: (1) invertebrates, (2) seeds, and (3) pollen/nectar berries and arils. Similarities were computed using the Renkonen-Whittaker index (Hurlbert, 1978). Values $\geqslant .50$ given in boldface. Comparisons involving $\mathrm{G}$. difficilis from Genovesa use an unweighted average of the diet proportions in two or three grids. Pinta diets used are for May (wet season) and for November (dry season). Island symbols as in Table 3.

\begin{tabular}{|c|c|c|c|c|c|}
\hline Sites & Season & $\begin{array}{l}\text { G. difficilis (G) } \\
\text { vs. diffilis (P) }\end{array}$ & $\begin{array}{l}\text { G. fuliginosa (P) } \\
\text { G. dis. } \\
\text { G. difilis (P) }\end{array}$ & $\begin{array}{l}\text { G. diffcilis (G) } \\
\text { vs. fuliginosa (P,M) }\end{array}$ & $\begin{array}{l}\text { G. fuliginosa (M) } \\
\text { G. fuliginosa (P) }\end{array}$ \\
\hline P1 & Wet & .63 & .46 & .72 & .98 \\
\hline P2 & Wet & .76 & .69 & .63 & .92 \\
\hline P3 & Wet & .72 & .45 & .61 & .90 \\
\hline P4 & Wet & .75 & .55 & .60 & .89 \\
\hline P5 & Wet & .54 & .32 & .55 & .86 \\
\hline P6 & Wet & .38 & - & - & - \\
\hline M1 & Wet & - & - & .75 & - \\
\hline M2 & Wet & - & - & .68 & - \\
\hline P1 & Dry & .21 & .18 & .94 & .92 \\
\hline P2 & Dry & .69 & .63 & .91 & .91 \\
\hline P3 & Dry & .27 & .25 & .93 & .90 \\
\hline P4 & Dry & .29 & .28 & .80 & .76 \\
\hline P5 & Dry & .10 & .05 & .72 & .46 \\
\hline P6 & Dry & .09 & - & - & - \\
\hline M1 & Dry & - & - & .82 & - \\
\hline M2 & Dry & - & - & .84 & - \\
\hline
\end{tabular}

3). These results, together with plant similarity data, indicate that Genovesa is quite different from sites on Pinta where $G$. difficilis is most common. This contradicts the FFR hypothesis.

From the FFR hypothesis, we also expect the density of $G$. difficilis on Genovesa to be determined by the same food resources which predict the density of this species on Pinta. This is tested using data from the dry season, when food was most likely to be limiting (cf. Smith et al., 1978; Schluter, 1982 b). Figure 3A compares the abundance of $G$. difficilis in sites on Genovesa in September to the regression of $G$. difficilis density in Pinta sites on the abundance of its preferred food there, ground invertebrates. The result indicates that in two of three sites $G$. difficilis is significantly more abundant on Genovesa than expected. In contrast, the dry season density of Marchena G. fuliginosa is quite accurately predicted by the Pinta food supply regression for this species (Fig. 3B).

The comparison in Figure $3 \mathrm{~A}$ is based upon a regression which uses means from the census transect data. Exactly the same result was obtained using total captures by mist-netting instead. Geospiza difficilis breeding density (number of territories) in the wet season on Genovesa was also higher than expected in two sites when compared with Pinta values using a similar analysis. In both cases values for $G$. fuliginosa on Marchena were close to the predicted values from Pinta regressions. In addition, when the comparison given in Figure 3A was repeated including also density of ground seeds (cf. Fig. 4) the pattern was the same. These data contradict the FFR hypothesis.

In a third test of the FFR hypothesis we compared the diets of $G$. difficilis on Genovesa and on Pinta. Table 4 lists the similarity in diets of these two populations in a variety of sites. The proportion of time that individuals spent feeding on the three general classes of foods, seeds, invertebrates, and pollen/nectar-berries/arils, is compared in two seasons. As shown (Table 4), similarity between the different $G$. difficilis populations was quite high in the wet (breeding) season and low in most sites in the dry season. In both seasons their 
diets were as dissimilar as diets of the different species $G$. fuliginosa and $G$. difficilis, in the same sites on Pinta.

The basis for these similarity values is shown in Figure 4 in which we compare diet proportions but further subdivide the diet categories to reveal differences in foraging position between the populations. Only site $1(110 \mathrm{~m})$ for Pinta is given since habitat similarity with Genovesa is greatest here (Table 3); however results are similar when other sites are used.

Observe that this subdivision enhances the differences between the two populations of $G$. difficilis (Fig. 4). In most sites, arthropods and gastropods removed almost exclusively from the litter predominated in the diet on Pinta year-round. Seeds were also frequently taken from the litter but only occasionally from the vegetation. Fleshy parts of fruits (berries and arils) and pollen and nectar were almost never taken by $G$. difficilis on Pinta. In contrast, $G$. difficilis on Genovesa was more opportunistic and fed in a wider diversity of ways (Fig. 4). Both seeds and invertebrates (chiefly arthropods) were removed more frequently from the vegetation, and pollen/nectar and berries/arils were important diet constituents. Seasonal trends also differed in the two populations. In most sites on Pinta ground invertebrates became more important than seeds in the diet in the dry season, whereas the reverse was true on Genovesa. These opposing trends largely account for the sharp decline in diet similarity in the dry season (Table 4).

Clearly the availability of different foods affected the diets of all populations. $\mathrm{Nu}$ merous examples of this are given in Schluter (1982a, 1982b). However many of the major diet differences between the two populations of $G$. difficilis apparently did not result from proximal responses to differences in availability of foods. For example, Figure 5 compares the proportion of arthropods and gastropods in the dry season diet of $G$. difficilis with their availability in the ground, relative to the diet proportion and availability of seeds. The

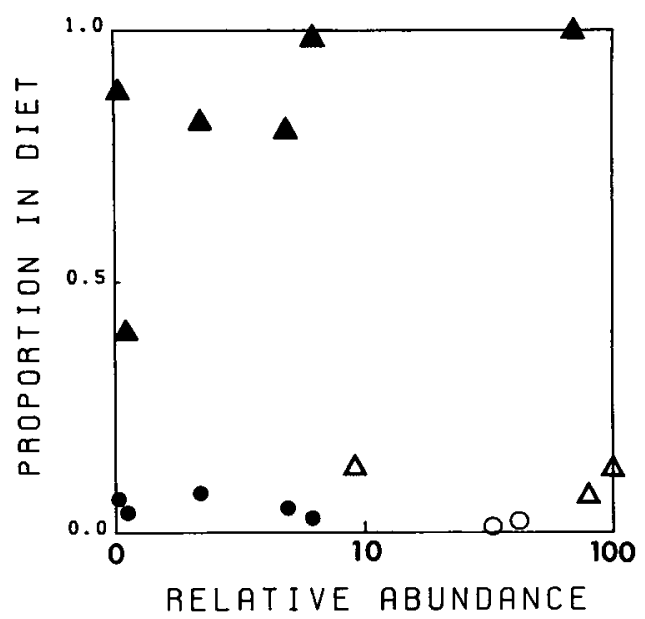

FIG. 5. Use of invertebrates by $G$. difficilis and $G$. fuliginosa in the dry season compared with availability, relative to small seeds (see Table 5 for definition). Diet refers to the amount of time spent feeding on invertebrates as a proportion of total time spent feeding on invertebrates and seeds. Relative abundance is the ratio of densities (mean dry weights) of litter invertebrates to small seeds, scaled to a percentage of the maximum value recorded. This ratio could not be analyzed statistically, but heterogeneity among the sites in the density of both litter invertebrates and seeds is significant (Kruskal-Wallis, $\boldsymbol{P}<$ $.001)$. Pinta values are from November. Symbols are $G$. difficilis on Pinta $(\Delta)$ and Genovesa $(\Delta)$, and $G$. fuliginosa on Pinta (O) and Marchena (O).

figure shows that, while Pinta G. difficilis consumed invertebrates more often than seeds over most of the range of availabilities, on Genovesa the species selected seeds. This was observed despite a comparable relative availability (biomass) of ground invertebrates there at that time.

The comparison in Figure 5 is based on estimates of total biomass of food types within sites. A similar result was obtained using estimates of the abundance of patches within which these foods are found; patch abundance is often a better predictor of diet than is total food biomass (Schluter, 1982a). The frequency of ground samples containing arthropods (a measure of patch abundance) was very similar on Genovesa (20-40\%) and lowland Pinta (32$48 \%$ ) in the dry season. Values were greater in the Pinta highlands. The frequency 
TABLE 5. Densities of foods important in the diet of G. fuliginosa. Pinta and Marchena values refer to densities in the two lowest sites on each island. Genovesa values are averages over sites. Heterogeneity among sites in the density of small seeds is significant in both seasons (Kruskal-Wallis, $\mathrm{P}<.001$ ). Intersite variation in flower abundance is significant in the dry season $(\mathrm{P}=.015)$ but not in the wet season $(\mathrm{P}=.844)$.

\begin{tabular}{lllcc}
\hline & & & \multicolumn{2}{c}{ Food supply } \\
\cline { 3 - 5 } \multicolumn{1}{c}{ Island } & Month & Season & $\begin{array}{c}\text { Small seeds } \\
\left(\mathrm{mg} / \mathrm{m}^{2}\right)^{\mathrm{a}}\end{array}$ & $\begin{array}{c}\text { Flowers } \\
(\text { No./M })^{\mathrm{b}}\end{array}$ \\
\hline Pinta & Feb. & Wet & $426.6-254.8$ & $0.0-0.0$ \\
Genovesa & Mar. & Wet & 109.4 & 0.0 \\
Marchena & Apr. & Wet & $10.3-190.9$ & $1.8-0.0$ \\
Pinta & May & Wet & $542.8-659.0$ & $0.0-1.0$ \\
Pinta & Aug. & Dry & $27.1-66.5$ & $0.4-0.1$ \\
Genovesa & Sept. & Dry & 9.4 & 0.8 \\
Marchena & Nov. & Dry & $5.0-6.2$ & $2.7-0.0$ \\
Pinta & Dec. & Dry & $23.9-35.1$ & $2.6-0.6$ \\
\hline
\end{tabular}

a Includes seed species preferred by $G$. fuliginosa on Pinta or Marchena. Genovesa total also includes Eragrostis cilianensis, a preferred seed of $G$. difficilis there. Preferred seeds are defined as those whose seed of $G$. difficilis there. Preferred seeds are defined as those whose
proportional representation in the diet was at least 1.5 times their proportional representation in the diet was at least 1.5 times their
proportional (numerical) abundance in samples (cf. Abbott et al., 1977; Schluter, 1982b). This category includes all foods commonly eaten. $b$ Includes flower species used by $G$. fuliginosa for nectar or pollen on Pinta or Marchena.

of samples wherein small seeds were recorded ranged from $16-72 \%$ in Genovesa sites, and from $67-80 \%$ on Pinta (excluding the highest site which had small seeds in only $25 \%$ of the samples). Hence the abundance of invertebrate patches relative to the abundance of seed patches on Genovesa was as high as in most Pinta sites in the dry season. Nonetheless, $G$. difficilis on Genovesa concentrated on seeds, unlike the same species on Pinta which ate mainly invertebrates (Fig. 5).

Differences in the types of invertebrates available do not either fully account for the diet differences; each order of arthropods encountered in the ground samples on Genovesa was seen to be eaten by $G$. difficilis on Pinta (gastropods are rare on Genovesa, as in lowland Pinta sites). Moreover the same result was observed when we looked at nectar and pollen in the diet and available in the habitat, relative to ground invertebrates. On Pinta, flowers yielding nectar or pollen were frequently more common than on Genovesa (Table 5), yet $G$. difficilis exploited them only on the latter island. These data indicate that the diet of $G$. difficilis varies between the two islands to a degree not proximally due to differences in food availability. Consequently fixed speciesspecific food requirements do not appear to exist in this species, and the FFR hypothesis is again contradicted.

\section{Variable Food Requirements Hypothesis}

The VFR hypothesis allows for some unspecified variation in the food requirements of a species on different islands, as an evolutionary response to different environments. Diet shifts evident in $G$. difficilis on Genovesa may be interpreted in this way. To explain the distribution of this species in relation to $G$. fuliginosa, however, the argument supposes that presently the bounds of this variation are such that on low islands one species cannot survive where the other is found. This would not be due to competitive exclusion, but rather to some deficiency in the habitat. This hypothesis is tested by examining the suitability of Genovesa for $G$. fuliginosa, and Marchena for $G$. difficilis.

Seed-plant composition in sites on Genovesa, where G. fuliginosa is absent, is compared with that on Pinta and Marchena in Table 3. As noted before, similarity between sites on the first island and lowland Pinta is high. This is true also of the similarity between Genovesa and Marchena, especially for the low altitude site on the latter island. Indeed, similarities between Genovesa and Marchena and lowland Pinta are as high as similarity between P1, the lowest site on Pinta, and P5, two sites where $G$. fuliginosa is very common in the dry season (Table 2). Consequently, at this level of analysis there is little reason to suppose that Genovesa is unsuitable for $G$. fuliginosa.

Also important is the amount of food on Genovesa. On Pinta and Marchena the major portion of the diet of $G$. fuliginosa was small seeds (Fig. 4). In the dry season its density in study sites on Pinta was closely attuned to the abundance of this food (Fig. 3B; $r=.84, P<.01$ ). Nectar was also important in the dry season, and 
this food source was exploited by $G$. $f u$ liginosa whenever it was available (Fig. 4). Table 5 shows the abundance of small seeds and nectar-producing flowers on the three islands. Seed supplies on Genovesa were usually at least as large as those in Marchena sites, and nectar supplies were similar to those at lowland Pinta sites at comparable dates. Sites wherein $G$. fuliginosa was common on the latter two islands frequently had lower nectar availabilities than Genovesa (e.g., this food was absent from site 5 on Pinta year-round). Therefore Genovesa does not appear to be deficient in either of these important $G$. fuliginosa foods.

Specific types of seeds and flowers on Genovesa are also similar to those exploited by $G$. fuliginosa elsewhere. The seed of Croton scouleri was one of the most abundant types on this island, and Trichoneura lindleyana seeds were also common. The first of these seed types was very important in the diet of $G$. fuliginosa on Marchena (32\% of its seed diet in site 1), and the second was highly preferred in lowland sites on both this island and Pinta. Additionally, the predominant source of nectar for $G$. fuliginosa on Marchena and in some sites on Pinta was Waltheria ovata; this was the most abundant nectaryielding flower on Genovesa. The fleshy aril of Bursera graveolens was another important wet season food for $G$. fuliginosa in lowland sites on Pinta and Marchena. This food is also abundant on Genovesa (unpubl. data; Abbott et al., 1977; Grant and Grant, 1980).

Thus there is evidence that conditions on Genovesa are suitable for the survival of $G$. fuliginosa. Breeding requirements also seem to be met. Seeds, caterpillars and other arthropods (e.g., arachnids) predominate in the diet of nestling $G$. $f u$ liginosa (unpubl. data); all these foods are abundant on Genovesa in the wet season (Table 5; Grant and Grant, 1980).

In addition we can identify nothing unique about Genovesa that would explain the presence of $G$. difficilis there but its absence from other lowland islands. The above results have shown seed-plant com- position and litter volume are similar on Genovesa and Marchena (e.g., Tables 3, 5). Moreover every species of seed, fruit and flower that $G$. difficilis exploited on Genovesa was present in Marchena sites with only two exceptions, the seeds of $\mathrm{He}$ liotropium angiospermum and Eragrostis cilianensis. The first is not common or important in the diet of Genovesa $G$. difficilis (0-3\% of diet; see also Abbott et al., 1977; Grant and Grant, 1980), and the second is unlikely to be a critical determinant of distribution since it is absent also from Pinta. A related species, $E$. mexicana, is present on Pinta, and eaten by $G$. fuliginosa there, but it is ignored by $G$. difficilis. These data contradict the VFR hypothesis.

\section{Competition Hypothesis}

Lack's hypothesis explains the distribution of $G$. difficilis in relation to $G$. $f u$ liginosa as the result of interspecific competition. It assumes that $G$. difficilis has adapted to local food conditions on low islands, and suggests that the two species cannot coexist on low islands because their food requirements there are too similar. The hypothesis assumes that food supply conditions are similar on Genovesa, Marchena, and lowland Pinta, and this assumption is strongly supported by data presented earlier (e.g., Tables 3, 5). The hypothesis predicts that the allopatric population of $G$. difficilis on Genovesa should be similar in diet and density to $G$. fuliginosa.

To test this we first compared the diets of different populations of these species. Table 4 lists similarity in diets between Genovesa $G$. difficilis and $G$. fuliginosa in Pinta and Marchena sites on three diet categories. Similarity is high, as expected from the competition hypothesis, especially in the dry season. Similarity values are comparable to those obtained when different populations of one species, $G$. $f u$ liginosa, are compared (Table 4).

Figure 4 subdivides the diet categories and illustrates the basis for the similarities between the two species in allopatry. Geospiza difficilis on Genovesa and $G$. 


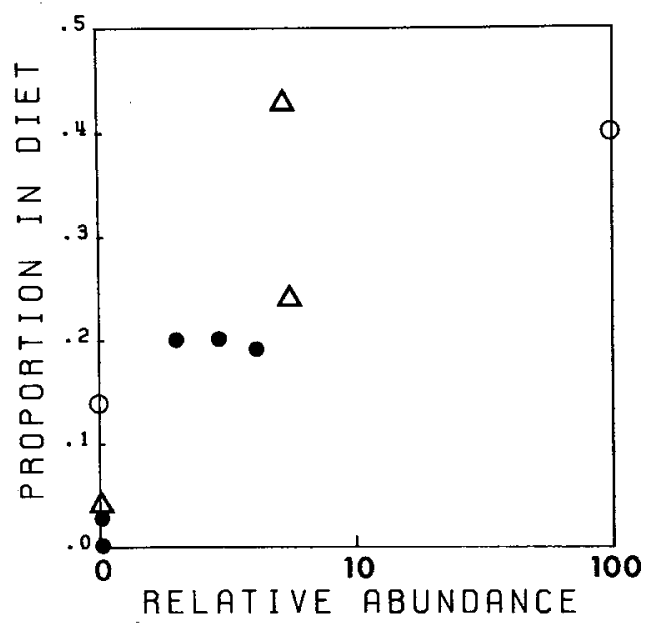

FIG. 6. Use of nectar and pollen by $G$. fuliginosa and $G$. difficilis in the dry season compared with availability, relative to small seeds (Table 5). Diet refers to the amount of time spent feeding on nectar/ pollen as a proportion of total time spent feeding on this and seeds. Relative abundance is the ratio of density of nectar/pollen-producing flowers to the abundance of small seeds, scaled to a percentage of the maximum value recorded. Heterogeneity among sites in the density of small seeds is significant (Kruskal-Wallis, $P<.001$ ) and in the number of flowers is nearly significant $(P=.058)$. Pinta values are from November. Symbols are $G$. difficilis on Genovesa $(\triangle)$ and $G$. fuliginosa on Pinta $(\Theta)$ and Marchena (O).

fuliginosa on Marchena and Pinta concentrated mainly on seeds in the dry season and these were removed from both the vegetation and the ground. Croton scouleri was very important in the diet of $G$. difficilis $(26-45 \%$ of seed diet in the dry season), as it was for $G$. fuliginosa on Marchena (see earlier). Invertebrates were also obtained from the ground and vegetation (Fig. 4).

Certainly the availability of invertebrates and seeds will influence the diets and hence the similarity observed. Figure 5 shows that $G$. difficilis on Genovesa responds in much the same way that $G$. $f u$ liginosa does elsewhere to the relative abundance of these two foods, but $G$. difficilis on Pinta does not. Geospiza diffcilis on Genovesa and $G$. fuliginosa elsewhere also both feed on nectar, especially from Waltheria ovata flowers (Fig. 4).
Availability influences the diet proportions observed, and Figure 6 indicates that $G$. difficilis on Genovesa may respond in a similar way to the relative abundance of nectar-yielding flowers and small seeds as $G$. fuliginosa does. In contrast, $G$. difficilis on Pinta did not consume nectar in any site (e.g., Fig. 4) These data strongly suggest that $G$. difficilis has converged in its feeding habits to $G$. fuliginosa in a similar environment.

In a second test we compared the dry season density of $G$. difficilis on Genovesa with that expected for $G$. fuliginosa on the basis of food supply (Fig. 3b). In all three sites $G$. difficilis occurs in approximately the density predicted, as does $G$. fuliginosa on Marchena. In this comparison we used census walk data; the result was similar when we used netting totals per site instead. We also found that on Genovesa the density of $G$. difficilis territories in the breeding season corresponded to that expected for $G$. fuliginos $a$ on the basis of seed density. These data suggest that the population density of $G$. difficilis on Genovesa is determined by the abundance of the same food type that determines the density of $G$. fuliginosa on Pinta and Marchena. The prediction of greater similarity on a lowland island is therefore met and the competition hypothesis is supported.

\section{Discussion}

The results show that the feeding habits of $G$. difficilis on Genovesa are quite different from those of $G$. difficilis on Pinta. These differences do not appear to be proximally caused by differences in the relative availabilities of foods on the two islands. Rather an evolutionary shift in diet preference seems to have occurred, probably as a response to the different food conditions on Genovesa. Moreover, seedplant composition of Genovesa appears no more different from composition on Marchena than seed composition on Marchena is from composition in lowland sites on Pinta. All three islands provide similar supplies of foods in the lowlands, and there is no reason to believe that a lack of appropriate diet items has played a role in 
shaping the presence/absence of $G$. difficilis and G. fuliginosa on these islands. In addition we see strong indication that $G$. difficilis on Genovesa has converged in diet on $G$. fuliginosa in a similar environment, in the absence of this species. Presently the best predictor of diet and density of $G$. difficilis on Genovesa is the diet and density of $G$. fuliginosa on other islands, and not the diet and density of $G$. difficilis on Pinta.

We conclude that the two hypotheses based upon food requirements of species and food characteristics of different islands do not account for the distribution of $G$. difficilis in relation to $G$. fuliginosa among Galápagos islands. The data are consistent with Lack's hypothesis of interspecific competition and we accept his as the superior of the three alternatives investigated.

Our interpretations do not critically depend on a detailed knowledge of the history of ecological shifts in $G$. difficilis. We do not have information to judge whether the species has actually converged in allopatry with $G$. fuliginosa, diverged in sympatry, or both. It is also difficult to assess with the data the degree to which competition with $G$. fuliginosa may have effected these shifts. To test the possibility of ecological character displacement or release we require a highland zone with only $G$. difficilis present, or a lowland island with both species. Neither situation exists. Nonetheless we have shown that $G$. difficilis is capable of colonizing and adapting to lowland islands where $G$. fuliginosa is usually found. Our tests suggest that $G$. fuliginosa has played a major role in restricting the number of islands presently occupied by $G$. difficilis.

Our conclusions, largely about past competitive exclusion between $G$. difficilis and $G$. fuliginosa, are based on an investigation of present-day characteristics of islands and species. Experimental introductions or manipulations of food supply are alternative and more controlled ways in which hypotheses about past events may be tested (e.g., Grant, 1969; Hairston, 1980). Our study of the finches has not been experimental because of limitations in this system. The great mobility of these birds would render introductions, on the scale necessary for realism, impractical and difficult to control. Nevertheless, we have shown that a detailed field study has the potential of choosing among alternative hypotheses for a distributional pattern.

Our conclusions rest upon the assumption that the populations of finches have been correctly classified by taxonomists. Cross-breeding experiments have never been conducted, so we have little way of knowing whether the populations of $G$. difficilis on Genovesa and Pinta are distinct species or not. For this study, the exact status of the different populations is not critical, as long as $G$. difficilis populations are more closely related to each other than to $G$. fuliginosa. This seems certain to be true (Bowman, 1961; Lack, 1969). Presently the populations of $G$. difficilis on Genovesa and Pinta are grouped in the same subspecies (Fig. 1; Lack, 1947), and recent behavioral work (Ratcliffe, 1981; Bowman, in press) has revealed that the population on Genovesa shares characteristics in song structure with other $G$. difficilis populations.

Recently another general hypothesis to explain distributional patterns of birds in the Galápagos has been suggested, that of "randomness" (Connor and Simberloff, 1978; Strong et al., 1979). The basic argument is that purely independent colonization and extinction rates for different species will produce many of the patterns which are presently seen and which have been attributed to competition (see also Simberloff, 1978). The authors have presented several statistical tests in support of their hypothesis, although these have been criticized (Grant and Abbott, 1980; Hendrickson, 1981).

We do not see "randomness" as a very likely explanation for the distribution of $G$. difficilis in relation to $G$. fuliginosa. There are 25 islands without a highland zone in the Galápagos (listed in Grant and Schluter, in press); three of these have $G$. difficilis populations only, 20 have $G$. $f u$ liginosa only, and two islands have nei- 
ther species. The probability of such an arrangement (when three populations of $G$. difficilis and 20 of $G$. fuliginosa are placed randomly and independently on 25 islands) is small ( $P=.004)$. Undoubtedly this figure is an overestimate, for why should G. difficilis be found on only three low islands to begin with? Poor colonizing ability (Simberloff, 1978) is not the explanation since this species occurs in the lowlands on only the most isolated islands (Fig. 1), which are presumably the most difficult to reach. For this reason, and because the two species are very similar in allopatry, we adhere to our conclusion that the distribution of $G$. difficilis in relation to $G$. fuliginosa in the Galágapos is partly a result of species interactions (interspecific competition), and it is not simply a product of chance.

A final question we address is how did the present pattern of occurrences arise? Lack (1947) argued that $G$. difficilis was probably an older species, on the basis of a high degree of racial differentiation (Fig. 1) and primitive plumage characteristics. He suggested from the distributional pattern that the more recent $G$. fuliginosa had excluded $G$. difficilis from all low islands where they had come into contact. This explains the absence of the latter species from all the central low islands despite potential source populations on some high islands (Fig. 1). However, it implies that the only reason $G$. fuliginosa has not yet excluded $G$. difficilis from the outer low islands is that there has not been enough time. Lack (1969) later changed his argument on the basis of a few specimens of $G$. fuliginosa having been collected from the distant island of Wolf (Fig. 1). He reasoned that $G$. fuliginosa has probably reached the outer islands frequently in the past. To explain the absence of breeding populations of $G$. fuliginosa on the outer islands he suggested instead that $G$. difficilis was more of a generalist than $G$. fuliginosa and hence competitively superior on the remote islands where resource diversity is likely to be low. However, neither the assumptions of $G$. difficilis being the more generalist species nor the assumption of outlying islands providing a very reduced diversity of foods is supported by our data from Marchena and Genovesa. Why, then, has G. fuliginosa not established a breeding population on the outer islands? On the basis of the results of our tests we suggest that the presence of $G$. difficilis may make it difficult for $G$. fuliginos $a$ to colonize, especially the outer islands where immigrants would be likely to arrive infrequently and in small numbers. Thus distance may influence the competitive process by determining the rate of immigration of $G$. fuliginosa, and give $G$. difficilis an advantage on islands it already occupies that are far from the center of the archipelago. Conceivably a combination of effects of distance and prior occupancy similarly explains the apparently stable persistence of $G$. conirostris on peripheral islands (Grant and Grant, 1982).

Our test may be of general significance. Patterns of the kind investigated here have been described for avian systems elsewhere (e.g., Bock, 1970; Terbough, 1971, 1973; MacArthur et al., 1972; Lack, 1973; Diamond, 1975) and for many other taxa. Competition for food is frequently cited as an explanation for these patterns, but rarely are food availability and diets studied directly. We suggest that our method of investigation has widespread applicability either as groundwork for later experimentation, or as substitutes for experiments when these are not feasible.

\section{SUMMARY}

The two finch species, Geospiza diffcilis and $G$. fuliginosa, are allopatric on low islands in the Galápagos archipelago, and they show a separation in their altitudinal ranges when they co-occur on islands with a highland zone. We tested three hypotheses which explain this distribution: 1) fixed species-specific food requirements (FFR) and island differences in food supply; 2) variable food requirements for different populations of the same species (VFR), but distributional ranges 
limited by the unsuitability of certain islands; and 3) interspecific competition for food, and competitive exclusion on low islands. Field studies conducted in the wet and dry seasons on three Galápagos islands support the competition hypothesis. Lowland sites on the different islands are similar in vegetation, substrate characteristics and food supply. Food requirements for $G$. difficilis vary on different islands, and this species is similar in diet and density with $G$. fuliginosa on the lowland island of Genovesa, where $G$. fuliginosa is absent. We observed that the diet and density of $G$. difficilis on Genovesa is predicted by these same attributes of $G$. $f u$ liginosa on two other islands, Pinta and Marchena, and not by the diet and density of $G$. difficilis on Pinta. The results contradict the predictions of the FFR and VFR hypotheses and we accept competition as the best explanation for the distributional pattern. We suggest that our procedures might be fruitfully applied to investigate the importance of the competitive process in other animal communities.

\section{ACKNOWLEDGEMENTS}

We thank Ron Brooks, Margaret Kinnaird, Stephen Millington, Felipe Rubio, and Hernan Vargas for their assistance in the field. The study benefitted greatly from numerous discussions with Beverly Rathcke. Trevor Price, Beverly Rathcke, and Robert Ricklefs commented on the manuscript. Logistic support was provided by the Charles Darwin Research Station. Funding came from an NSF grant (DEB 77-23377) to PRG and a Frank M. Chapman grant to DS. The work was done with the permission of the Dirección General de Desarrollo Forestal, Quito.

\section{Literature Cited}

Aвbott, I., L. K. Aвbott, and P. R. Grant. 1977. Comparative ecology of Galápagos ground finches (Geospiza Gould): evaluation of the importance of floristic diversity and interspecific competition. Ecol. Monogr. 47:151-184.

Adsersen, H. 1976. A botanist's notes on Pinta. Noticias de Galápagos 24:26-28.

BoAG, P. T. 1981. Morphological variation in the
Darwin's finches (Geospizinae) of Daphne Major Island, Galápagos. Ph.D. Thesis. McGill Univ., Montreal.

Bock, W. J. 1970. Microevolutionary sequences as a fundamental concept in macroevolutionary models. Evolution 24:704-722.

Bowman, R. I. 1961. Morphological differentiation and adaptation in the Galapagos finches. Univ. Calif. Berkeley Publ. Zool. 58:1-302.

. In press. The evolution of song in Darwin's finches. In R. I. Bowman and A. E. Leviton (eds.), Patterns of Evolution in Galápagos Organisms. Amer. Assoc. Adv. Sci., Pacific Division, San Francisco.

Connor, E. F., AND D. Simberloff. 1978. Species number and compositional similarity of the Galápagos flora and avifauna. Ecol. Monogr. 48:219-248.

Diamond, J. M. 1975. Assembly of species communities, p. 342-444. In M. L. Cody and J. M. Diamond (eds.), Ecology and Evolution of Communities. Belknap Press, Harvard Univ., Cambridge.

Grant, B. R., aND P. R. Grant, 1982. Niche shifts and competition in Darwin's finches: Geospiza conirostris and congeners. Evolution 36 : 637-657.

Grant, P. R. 1969. Experimental studies of competitive interaction in a two-species system. I. Microtus and Clethrionomys species in enclosures. Can. J. Zool. 47:1059-1082.

- In press. The role of interspecific competition in the adaptive radiation of Darwin's finches. In R. I. Bowman and A. E. Leviton (eds.), Patterns of Evolution in Galápagos Organisms. Amer. Assoc. Adv. Sci. , Pacific Division, San Francisco.

Grant, P. R., AND I. AввотT. 1980. Interspecific competition, island biogeography and null hypotheses. Evolution 34:332-341.

Grant, P. R., AND P. T. BoAg. 1980. Rainfall on the Galápagos and the demography of Darwin's finches. Auk 97:227-244.

Grant, P. R., AND B. R. Grant. 1980. The breeding and feeding characteristics of Darwin's finches on Isla Genovesa, Galápagos. Ecol. Monogr. 50:381-410.

Grant, P. R., J. N. M. Smith, I. Abbott, AND L. K. Аввотт. 1976. Darwin's finches: population variation and natural selection. Proc. Nat. Acad. Sci. 73:257-261.

Grant, P. R., AND D. Schluter. In press. Interspecific competition inferred from patterns of guild structure. In D. R. Strong, D. S. Simberloff and L. G. Abele (eds.), Ecological Communities: Conceptual Issues and the Evidence. Princeton Univ. Press, Princeton.

Hairston, N. G. 1980 . Evolution under interspecific competition: field experiments on terrestrial salamanders. Evolution 34:409-420.

HendRICKSON, J. A., JR. 1981. Community wide character displacement reexamined. Evolution 35: 794-810. 
HurLbert, S. 1978. The measurement of niche overlap and some relatives. Ecology 59:67-77.

Lack, D. 1947. Darwin's Finches. Cambridge Univ. Press, Cambridge.

1969. Subspecies and sympatry in Darwin's finches. Evolution 23:252-263.

1973. The numbers of species of hummingbirds in the West Indies. Evolution 27:326337.

MacArthur, R. H., J. M. Dlamond, AND J. R. KARR. 1972. Density compensation in island faunas. Ecology 53:330-342.

RATClIFFe, L. M. 1981. Mate recognition and species discrimination in Darwin's Finches (Geospizinae). Ph.D. Thesis, McGill Univ., Montreal.

SCHLUTER, D. 1982a. Seed and patch selection by Galápagos ground finches: relation to foraging efficiency and food supply. Ecology 63:1106-1120. 1982b. Distributions of Galápagos ground finches along an altitudinal gradient: the importance of food supply. Ecology 63:1504-1517.

SIMBERLOFF, D. 1978. Using island biogeographic distributions to determine if colonization is stochastic. Amer. Natur. 112:713-726.
SMith, J. N. M., P. R. Grant, B. R. GRaNt, I. Аввотt, and L. K. Аввотt. 1978. Seasonal variation in feeding habits of Darwin's ground finches. Ecology 59:1137-1150.

Sørenson, T. 1948. A method of establishing groups of equal amplitude in plant sociology based upon similarity of species content and its application to analyses of the vegetation on Danish commons. Biologiske Skrifter 5:1-34.

STRONG, D. R., JR., L. A. SzySKA, AND D. S. SimBERLOFF. 1979. Tests of community-wide character displacement against null hypotheses. Evolution 33:897-913.

TERBOUGH, J. 1971. Distribution on environmental gradients: theory and a preliminary interpretation of distributional patterns in the avifauna of the Cordillera Vilcabamba, Peru. Ecology 52: 23-40.

1973. Chance, habitat and dispersal in the distribution of birds in the West Indies. Evolution 27:338-349.

Wiggins, I. L., AND D. M. Porter. 1971. Flora of the Galápagos Islands, Univ. Press, Stanford.

Corresponding Editor: R. Ricklefs 